\title{
Interés público y constitución giratoria
}

\author{
Mg. Arq. Juan Miguel Guerrero Orbegozo \\ miguelguerrerolima@ hotmail.com \\ ORCID: 0000-0001-5780-0824
}

Mg. Arq. Víctor Humberto González Acuña.

ORCID: 0000-0002-1774-9750

Mg. Arq. María Elena Soto Velásquez.

ORCID: 0000-0001-7388-4300

Mg. Ing. Guido Castillo Torres
ORCID: 0000-0002-6491-8740

Universidad Cesar Vallejo

Lima - Perú.

\section{RESUMEN}

Las políticas públicas, deben de partir del cumplimiento a la carta constitucional. En su artículo 65 , desde 1993 establece la garantía de Protección al consumidor. Sin embargo, en flagrante contradicción y evidente discriminación, el último párrafo del Artículo $62^{\circ}$, otorga garantías y seguridades, solo para un determinado tipo de contrato, los contratos-ley. Se puede establecer garantías y otorgar seguridades y no pueden ser modificados legislativamente. Están protegidos constitucionalmente. Esto, al colisionar con los artículos $1^{\circ}, 2.1^{\circ}, 2.2^{\circ}, 2.14^{\circ}$ y $59^{\circ}$ del mismo instrumento, evidentemente produce un conflicto en la estructura constitucional. ¿Es posible formular políticas públicas, en base a una constitución inconstitucional? En el Perú, sí. Lo venimos haciendo con los contratos ley, desde hace 28 años. Estamos ante una constitución giratoria.

Palabras clave: constitución; constitucional; agravio; interés público; discriminación. 


\title{
Public interest and revolving constitution
}

\begin{abstract}
Public policies must start from compliance with the constitutional charter. In its Public policies must start from compliance with the constitutional charter. In its article 65, from 1993 it establishes the consumer protection guarantee. However, in flagrant contradiction and evident discrimination, the last paragraph of Article 62, grants guarantees and assurances, only for a certain type of contract, the law-contracts. Guarantees can be established and guarantees can be granted and cannot be legislatively modified. They are constitutionally protected. This, when colliding with articles 1, 2.1, 2.2, 2.14 and 59 of the same instrument, evidently produces a conflict in the constitutional structure. Is it possible to formulate public policies, based on an unconstitutional constitution? In Perú, yes. We have been doing it with law contracts for 28 years. We are facing a revolving constitution.
\end{abstract}

Key words : constitution, constitutional, grievance, public interest, discrimination.

Artículo recibido: 10 Setiembre. 2021 Aceptado para publicación: 15 Octubre. 2021 Correspondencia: miguelguerrerolima@hotmail.com Conflictos de Interés: Ninguna que declarar 


\section{INTRODUCCIÓN}

Comparando las constituciones de los 34 países miembros de OCDE, la de Hungría, tiene solo ocho años de historia, es la más joven, mientras que Inglaterra tiene la más longeva: 804 años de edad. Comparando el número de palabras que contienen, la de México encabeza el ranking, con 57,087 palabras. La de Perú tiene hoy, 20,580 palabras y la de Islandia 4,089 palabras. Si se compara con la cantidad de derechos sociales que albergan, se puede ver que la de México contiene 81 derechos, la de Islandia 44 y la chilena -que tiene veintidós mil palabras más que la de Islandia- contiene 46 derechos sociales. (Cifuentes, 2019)

No hay una regla. Sin embargo, las constituciones deben ser coherentes y consagrar los derechos fundamentales, sin ellos la sociedad no va a funcionar. El 69.4\% de estos Estados, no aseguran y ni pagan la salud: Finlandia, Canadá, Estados Unidos y Australia. En tanto, Dinamarca, es la única que consagra el deber del Estado de dar trabajo. México que tiene el mayor número de palabras, tiene el nivel más bajo de cumplimiento de normas. Finlandia, con 12.640 palabras es el país con mayor índice de acatamiento de reglas. México es el país con menor índice de control de la corrupción.

Héctor Vargas Haya, en 1989 en la presentación del libro Constituciones Peruanas 1922-1979, afirma que le hubiese agradado más, tener una sola constitución como la norteamericana, que en ese momento cumplía 213 años o como la inglesa, que no está escrita, pero que aquellos la llevan en la mente y espíritu. Desde 1823, en el Perú se han promulgado 12 Constituciones Políticas. Las 8 primeras, en un periodo de 44 años. Las siguientes en 77 años, hasta $1993^{1}$. (Chipoco Tovar, 1989)

El poder del estado, debe orientarse al bienestar general. Ningún tipo de contratación especial, puede ser amparada constitucionalmente si su estructuración vulnera la legalidad; ante esta situación, de manera fáctica pierden su condición (los contratos ley). Por intereses de privados (ni siquiera del estado), no se le puede impedir al Poder Legislativo, ejercer su atribución constitucional. De ser así, la Carta Magna, estaría amparando la comisión de delitos y contraviniendo su propia estructura, que establece el trato igual para todos los ciudadanos, eliminando la posibilidad de discriminación, de cualquier índole.

El objeto de la investigación, es analizar el grado de corrupción reinante en el manejo del estado, como consecuencia de una grave falla en la estructura constitucional; analizaremos en

\footnotetext{
${ }^{1}$ La constitución la Carta Magna peruana, consta de 206 artículos, 16 disposiciones finales y transitorias, 03 transitorias especiales y una declaración del Congreso Constituyente.
} 
especial los contratos de asociación pública privada de infraestructura vial, que concita la atención ciudadana y representa un fenómeno de gran interés público. Mas aún, si desde la carta magna se les tendería a los actores, un explícito manto de impunidad. En teoría, nuestra normativa y el Magno Tribunal, cautelan el interés público² ${ }^{2}$

Durante estos últimos 28 años, muchos funcionarios públicos, han desfilado por los tribunales, de todo el Perú. ¿Creen ustedes, que por incapacidad? No. Todos, por haber recibido coimas para suscribir o ampliar contratos. Algunos fueron a la cárcel ${ }^{3}$. La mayoría, no. Pero los contratos siguen indemnes. ¿Estos contratos tienen valor legal? Lamentablemente, sí. Solo en un único caso, el contrato fue anulado ${ }^{4}$. Este es el caso más antiguo, de lo que a partir de ahí ha sucedido en el Perú, durante más de dos décadas. Tenemos que mirarnos en este espejo. Todo se ha hecho mal. Básicamente, por la falta de compromiso de los funcionarios públicos, que, al recibir la responsabilidad de suscribir contratos a nombre del estado, al amparo de un defecto constitucional evidente, privilegiaron una prebenda miserable, a los intereses de la población. Aceptaron condiciones ridículas, antitécnicas y perjudiciales.

De un simple análisis de la ejecución de algunos de los contratos de APP de infraestructura vial, observamos que actualmente existe un evidente desequilibrio económico financiero, que favorece notoriamente a los concesionarios. Sin perjuicio, de que se viene pagando tarifas (que los soportan económica y financieramente), que no responden a una estructura técnica, en agravio del interés público.

Además, en su totalidad, participan como concesionarios, miembros del tristemente célebre "club de la construcción" y evidencian actos de corrupción. No ha existido una inversión privada cabal y real, pues en la mayoría de las concesiones, los concesionarios disponen gratuitamente de la infraestructura vial existente. La mayoría, iniciaron cobranza de peajes, a la suscripción del contrato. No existe un reparto objetivo entre las partes ni sostenibilidad financiera ni ventajas socio económicas de los proyectos, por lo que los contratos agravian el interés público.

Pagar por un buen servicio, debería ser una garantía constitucional explicita. Hemos perdido el cabal sentido del gasto público. La academia, debe de sensibilizar este tópico. Ahora tenemos que hacer las cosas bien.

\footnotetext{
${ }^{2}$ Expediente $\mathrm{N}^{\circ}$ 0090-2004-AA/TC.

${ }^{3}$ La República. 02MAY2020. Alcaldes que terminaron en la cárcel.

${ }^{4}$ CIADI Caso No. ARB/10/2, 13MAY2013
} 


\section{ESTRATEGIAS METODOLÓGICAS}

\section{Se trata de una investigación:}

a) Cualitativa, holística, examina el mundo de la gestión pública peruana. Se desarrollará una teoría coherente con los datos recolectados, en base a una lógica y proceso inductivo. Iremos, de lo particular a lo general. Describiremos, las cualidades y calidades, de la contratación estatal y su amparo constitucional, los significados no se reducirán a números y el análisis, no será estadístico.

b) Básica, de aplicación inmediata, sobre hechos que suceden en este momento en el país.

c) No experimental, no manipularemos las variables, observaremos los procesos sin interrumpir, alterar o imponer un punto de vista externo, aceptando lo percibido por los actores, durante los últimos 28 años.

\section{Imagen 1: Metodología}

\section{TÉCNICAS E INSTRUMENTOS DE RECOLECCIÓN DE DATOS}

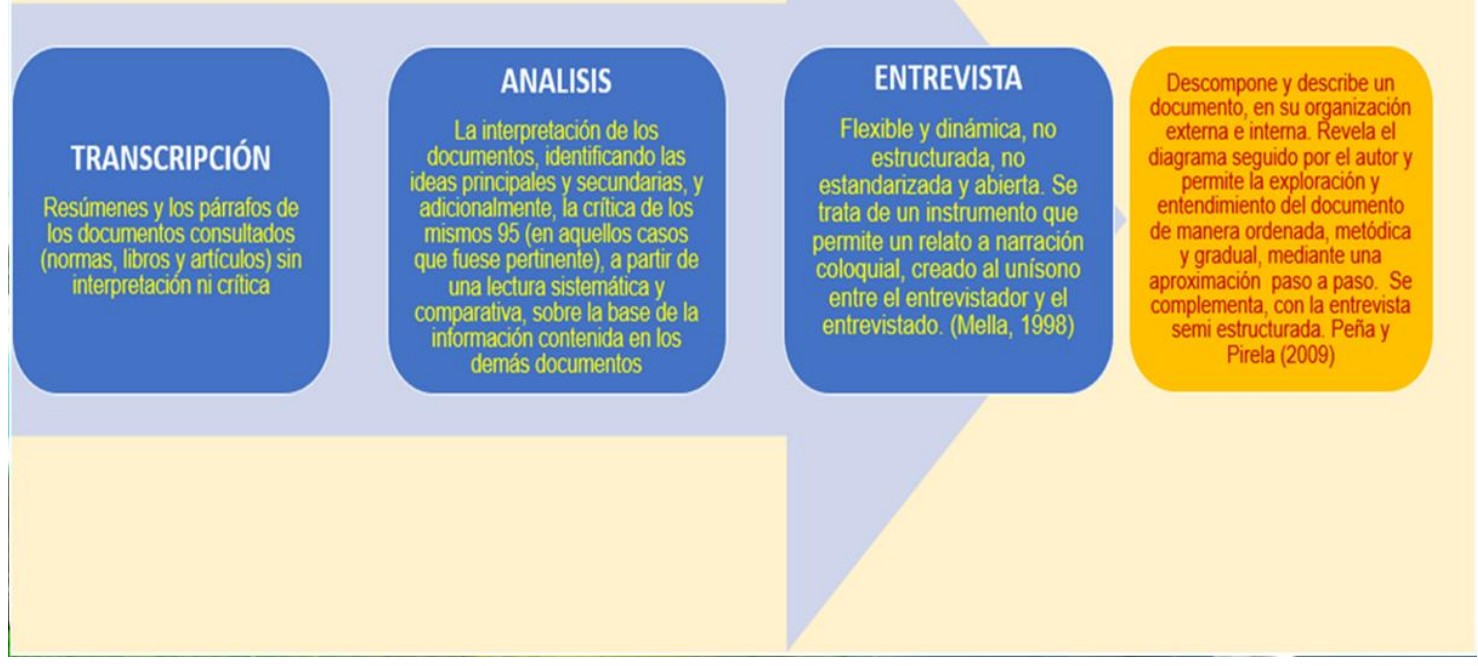

Fuente: Elaboración propia. (Hernandez Sampieri, Fernandez Collado, \& Baptista Lucio, 2014)

La investigación ha sido flexible en cuanto al modo de obtener la data. Se han seguido lineamientos orientadores, pero no reglas. Los métodos han estado al servicio del investigador; el investigador no estuvo supeditado a un procedimiento o técnica.

La constitución política del Perú de 1993, establece:

"Artículo 62 
(...) Mediante contratos-ley, el Estado puede establecer garantías y otorgar seguridades. No pueden ser modificados legislativamente, sin perjuicio de la protección a que se refiere el párrafo precedente.

Debemos determinar, cuál ha sido el efecto concreto de este defecto estructural, en su contradicción con los artículos $1^{\circ}, 2.1^{\circ}, 2.2^{\circ}, 2.14^{\circ}, 59^{\circ}$ y $65^{\circ}$ del mismo texto. Para ello, analizaremos dos tipos de casos.

\section{Primer tipo de casos.}

En el Perú, los contratos a los que se refiere el artículo 62 de la Carta Magna, son supervisados en cada caso, por el Organismo regulador del sector y por los diferentes niveles de gobierno. Solo mencionaremos las obras de infraestructura vial, que están bajo la competencia de sus organismos reguladores (Ositran, Invermet). En estos contratos, se evidencian un abuso de derecho que perjudica a la población. Para dar inicio a la investigación, consultamos virtualmente a 36 ciudadanos de todo el país y en el extranjero. El resultado nos arroja cifras sintomáticas.

\section{Imagen 2: Percepción de caos vehicular.}

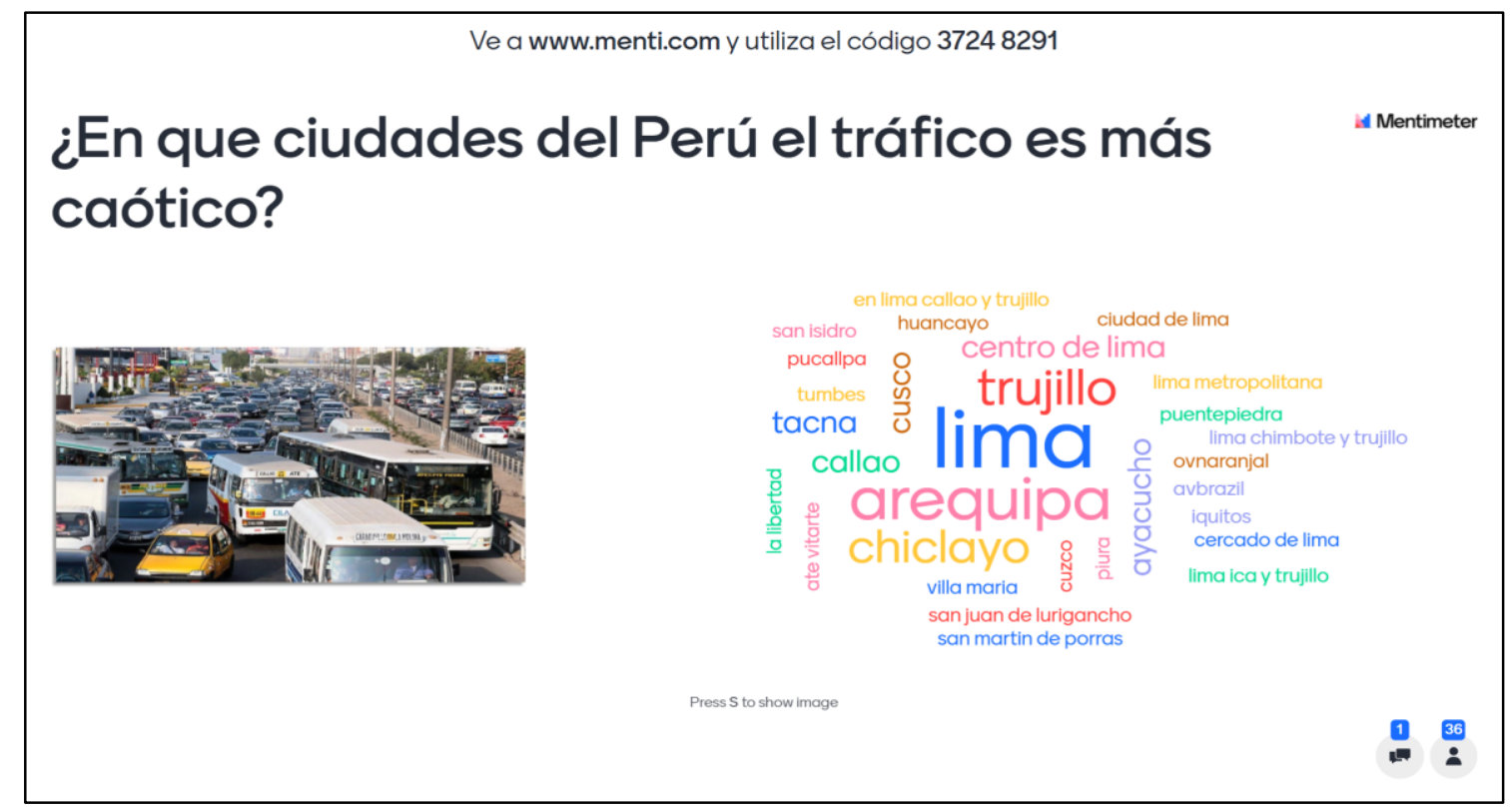

Fuente: Mentimetter voting code 3724 8291. 13AGO2021/16AGO2021

De la imagen 2, confirmamos de manera espontánea que, para estos ciudadanos, el caos en el tránsito vehicular, no es exclusividad de la capital. Los contratos que concesionan la infraestructura vial peruana, están bajo protección del artículo constitucional en cuestión. Esto permite que los contratos sigan vigentes y logren ganar arbitrajes internacionales, a pesar del 
descontento ciudadano, debido tarifas abusivas, que inclusive han sido el motivo de una condena a prisión de un funcionario público municipal. ${ }^{5}$

Imagen 3: Percepción sobre tarifas de peaje.

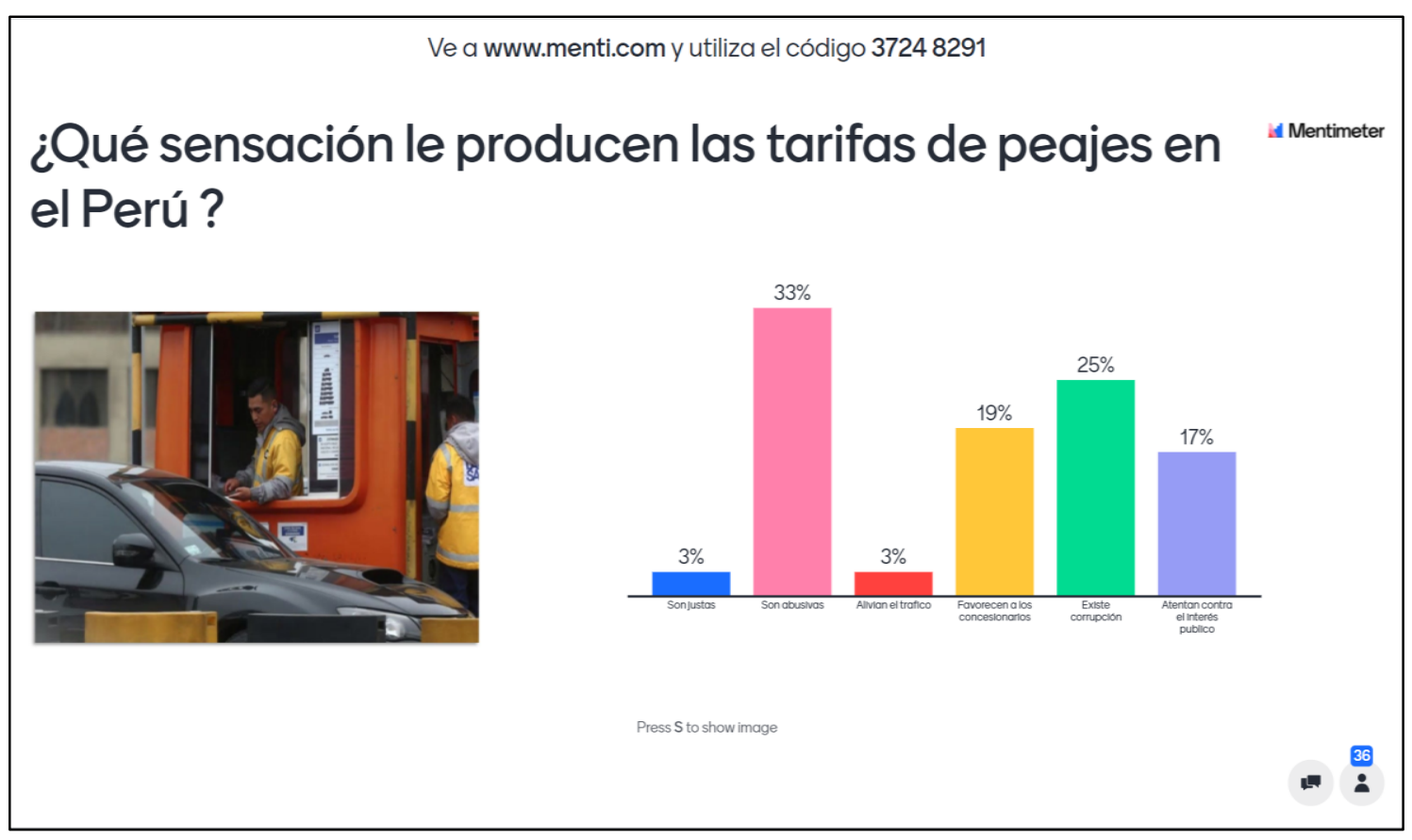

Fuente: Mentimetter voting code 3724 8291. 13AGO2021/16AGO2021

En la imagen 3, se aprecia que solo el $6 \%$ de los participantes, considera que las tarifas de peaje son justas o alivian el tráfico vehicular. El 94\% de los entrevistados, las considera lesivas para el país. Sin embargo, estos contratos gracias al amparo constitucional, seguirán vigentes entre 7 y 28 años más. La percepción ciudadana, se refleja en los números de la ejecución de los contratos en cuestión.

Pese a esta percepción, el grueso de los contratos de APP no ha informado a ninguna de las instituciones reguladoras, la existencia de algún desequilibrio económico financiero (DEF) en algún contrato, cuya visibilidad, garantizaría el respeto al interés público. Algo inusual, pues de existir este DEF, podría agraviar indistintamente el interés particular del concesionario o el interés público. La Jefatura de Fiscalización del OSITRAN atendió 72 expedientes sancionadores. Ninguno, reclama lo más importante: el restablecimiento del equilibrio económico financiero, de algún contrato.

\footnotetext{
${ }^{5}$ https://www.gob.pe/institucion/mpfn/noticias/451888-ministerio-publico-logro-carcel-efectiva-paraexfuncionario-de-municipalidad-de-lima
} 
En concordancia con la contradicción jurídica existente, en la siguiente tabla, apreciamos el detalle de un primer grupo de 8 de estos contratos de infraestructura vial, que se ejecutan desde el año 2003. (OSITRAN, 2021)

Tabla 1: Contratos autosostenibles en infraestructura vial. Datos en millones de dólares.

\begin{tabular}{|c|c|c|c|c|c|c|c|c|c|c|}
\hline \multicolumn{3}{|c|}{$\begin{array}{l}\text { INFRAESTRUCTURA } \\
\text { CONCESIONADA }\end{array}$} & \multicolumn{2}{|c|}{$\begin{array}{l}\text { PLAZO AÑOS } \\
\text { CONCESION }\end{array}$} & \multicolumn{3}{|c|}{ INVERSION } & \multicolumn{3}{|c|}{ BALANCE } \\
\hline CONTRATO & ZONA & $\begin{array}{c}\text { FECHA } \\
\text { CONCESION }\end{array}$ & TOTAL & FALTAN & $\begin{array}{l}\text { USD } \\
\text { CONTRACTUAL } \\
\text { CON IGV }\end{array}$ & $\begin{array}{l}\text { USD } \\
\text { AVANCE } \\
2021\end{array}$ & $\underset{\%}{\operatorname{AVANCE}}$ & PEAJES & BENEFICIO & $\%$ \\
\hline $\begin{array}{l}\text { Ancón-Huacho- } \\
\text { Pativilca }\end{array}$ & CENTRO & 2003 & 25 & 7 & 140.8 & 165.6 & 117.6 & 696.2 & 530.6 & 320.4 \\
\hline $\begin{array}{l}\text { Pucusana-Cero } \\
\text { Azul-Ica }\end{array}$ & CENTRO & 2005 & 30 & 14 & 258.8 & 234.3 & 90.5 & 798.6 & 564.3 & 240.8 \\
\hline Lima Expresa & CAPITAL & 2009 & 40 & 28 & 566.4 & 560.0 & 98.9 & $1,012.8$ & 452.8 & 80.9 \\
\hline $\begin{array}{l}\text { Vías Nuevas de } \\
\text { Lima }\end{array}$ & CAPITAL & 2013 & 33 & 25 & 588.6 & 388.6 & 66.0 & $1,274.0$ & 885.4 & 227.8 \\
\hline $\begin{array}{l}\text { Pativilca-Puerto } \\
\text { Salaverry }\end{array}$ & NORTE & 2009 & 25 & 13 & 286.2 & 196.1 & 68.5 & 577.0 & 380.9 & 194.2 \\
\hline Trujillo-Sullana & NORTE & 2009 & 25 & 13 & 492.6 & 334.5 & 67.9 & 431.5 & 97.0 & 29.0 \\
\hline $\begin{array}{l}\text { IIRSA Centro } \\
\text { Tramo } 2 \\
\end{array}$ & CENTRO & 2010 & 25 & 14 & 153.7 & 120.3 & 78.3 & 177.9 & 57.6 & 47.9 \\
\hline $\begin{array}{l}\text { Desvio Matarani - } \\
\text { Desvio Ilo Tacna }\end{array}$ & SUR & 2013 & 25 & 17 & 134.3 & 38.3 & 28.5 & 171.1 & 132.8 & 346.8 \\
\hline TOTALES & & & & & $2,621.4$ & $2,037.7$ & & $5,139.2$ & $3,101.5$ & 152.2 \\
\hline
\end{tabular}

Fuente: Elaboración propia, proyecciones con datos del Organismo Supervisor de Infraestructura de $r$ de la Inversión en Infraestructura de Transporte de Uso Público - OSITRAN; y el Fondo Metropolitano de Inversiones, INVERMET. Los montos incluyen IGV.

(1) Todos los contratos, se firmaron sobre carreteras existentes, empezaron a cobrar los peajes antes de culminar los trabajos, contaron con garantía del estado y sus intervinientes consorciados, forman parte del llamado "Club de la Construcción"

(2) Todos los contratos, han superado los 8 años de ejecución y solo uno ha culminado las obras.

(3) A pesar de ello, el $87.5 \%$ de los contratos, tienen un avance del $65 \%$ de avance de su obligación contractual y registran a la fecha, beneficios inusuales en el mercado internacional.

(4) Hasta la finalización de la concesión, solo uno de los contratos, de acuerdo a la proyección de sus EEFFAA, recaudaría más de 6,800 millones de dólares.

Han sido denominados convenientemente, como autosostenibles, cuando no lo son. Según $\mathrm{ESAN}^{7}$ los contratos son autosostenibles, cuando "están financiados por las tarifas que los propios usuarios pagan y por eso, no se requiere de recursos públicos para saldar la deuda que la compañía adquiere con el proyecto". Esta es la deformación, que es una de las razones que permite la protección constitucional. El concepto de auto sostenible que la normatividad peruana desconoce, debe de obligar al concesionario a invertir de su dinero, para desarrollar

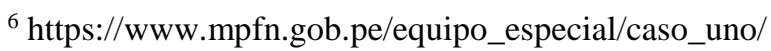

${ }^{7}$ https://www.esan.edu.pe/apuntes-empresariales/2018/04/app-cofinanciadas-y-autosostenibles-los-principiosentre-cada-clasificacion/
} 
la infraestructura vial y luego de entrar en funcionamiento el nuevo servicio, iniciar el cobro de peaje, que le permita recuperar su inversión y una utilidad razonable.

Adicionalmente, más importante: las tarifas de peaje son patrimonio municipal y estatal, por tanto, se tratan de recursos públicos. Al pagar su deuda con dinero recaudados de los peajes, los concesionarios están utilizando fondos públicos. Debemos agregar, que los concesionarios en su mayoría empezaron a disfrutar de la cobranza de los peajes, desde la suscripción de los contratos y en su mayoría, dispusieron de vías totalmente construídas por el estado, antes firmar los contratos.

\section{Imagen 4: Distribución de recaudación de peajes de carreteras concesionadas autosostenibles}

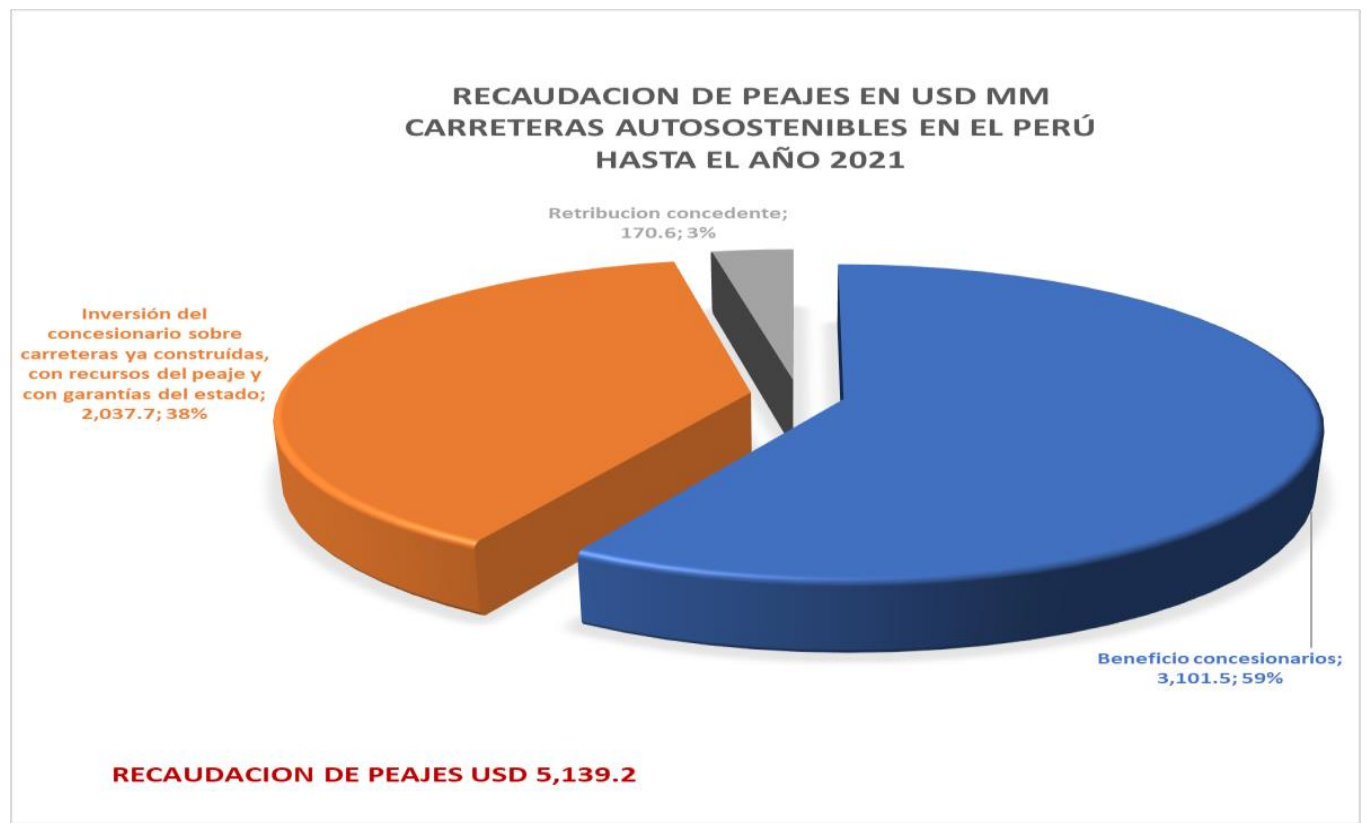

Fuente: Elaboración propia, proyecciones con datos del Organismo Supervisor de Infraestructura de $r$ de la Inversión en Infraestructura de Transporte de Uso Público - OSITRAN; y el Fondo Metropolitano de Inversiones, INVERMET. Sin identificar sobre precios ni actos de corrupción.

(1) Recaudación sobre carreteras existentes. Empezaron a cobrar los peajes antes de culminar los trabajos.

(2) Hasta el año 2021, el beneficio bruto de estos contratos calculado, asciende al $152.2 \%$ de lo invertido. Considerando que al firmar los contratos las pistas ya existían y que iniciaron el cobro de peajes al momento de suscribir los contratos, el beneficio de los concesionarios, es incalculable.

(3) Hasta el año 2049, de acuerdo con los EEFFAA de los concesionarios, la proyección de recaudación de peajes de estos contratos, se estima en 45,000 millones de dólares.

En la imagen 4, se aprecia la enorme desproporción de la distribución de beneficios, entre las partes. Esta situación evidencia un grave desequilibrio económico financiero de los contratos, que debe restablecerse. Lo que agrava el desequilibrio, es que el concedente aporta de forma gratuita la totalidad de la infraestructura, sobre la que se desarrollan los contratos. Y esta proporción se irá deformando año a año, a favor del concesionario. Los plazos de los contratos, en promedio vencen el 2035. Restan en promedio, 15 años de recaudación de peajes. 
El desequilibrio se incrementa, hacia la finalización de los contratos. Lo que agrava la situación, es que el concedente (el estado) aporta graciosamente en contratos con protección constitucional y sin costo para el concesionario, la totalidad de la infraestructura, sobre la que se desarrollarán los contratos. Esta situación solo se produce en el Perú y solo en los contratos ley. El segundo grupo de este primer tipo de casos, son los contratos llamados cofinanciados. En la siguiente tabla, apreciamos el detalle de 10 de estos contratos. (Pari, 2016)

Tabla 2: Contratos de infraestructura vial cofinanciados.

\begin{tabular}{|c|c|c|c|c|c|c|c|c|c|}
\hline \multicolumn{3}{|c|}{ INFRAESTRUCTURA CONCESIONADA } & \multicolumn{2}{|c|}{$\begin{array}{c}\text { PLAZO } \\
\text { AÑOS } \\
\text { CONCESION }\end{array}$} & \multicolumn{5}{|c|}{ BALANCE } \\
\hline CONTRATO & ZONA & $\begin{array}{l}\text { FECHA } \\
\text { CONCESION }\end{array}$ & TOTAL & FALTAN & $\begin{array}{l}\text { USD } \\
\text { CONTRACTUAL } \\
\text { CON IGV }\end{array}$ & $\begin{array}{l}\text { USD } \\
\text { AVANCE } \\
2021\end{array}$ & $\underset{\%}{\operatorname{AVANCE}}$ & PEAJES & $\begin{array}{l}\text { PAO, } \\
\text { PAMO, } \\
\text { CPRPAO }\end{array}$ \\
\hline IIRSA Norte & $\begin{array}{l}\text { COSTA } \\
\text { SIERRA } \\
\text { SELVA } \\
\text { NORTE } \\
\end{array}$ & 2005 & 25 & 9 & 641.4 & 574.4 & 89.6 & 243.9 & 875.6 \\
\hline IIRSA Sur Tramo 2 & $\begin{array}{l}\text { SELVA } \\
\text { SUR }\end{array}$ & 2005 & 25 & 9 & 701.0 & 669.8 & 95.5 & NO INICIA & 849.8 \\
\hline IIRSA Sur Tramo 3 & $\begin{array}{l}\text { SIERRA } \\
\text { SUR }\end{array}$ & 2005 & 25 & 9 & 687.4 & 636.1 & 92.5 & 70.2 & $1,043.2$ \\
\hline IIRSA Sur Tramo 4 & $\begin{array}{c}\text { SIERRA } \\
\text { SUR }\end{array}$ & 2005 & 25 & 9 & 633.7 & 793.1 & 125.2 & 46.5 & 798.3 \\
\hline Buenos Aires Canchaque & $\begin{array}{l}\text { COSTA } \\
\text { NORTE }\end{array}$ & 2007 & 15 & 1 & 40.0 & 37.6 & 94.0 & 4.2 & 120.2 \\
\hline IIRSA Sur Tramo 1 & $\begin{array}{c}\text { COSTA } \\
\text { SUR }\end{array}$ & 2007 & 25 & 11 & 145.4 & 152.1 & 104.6 & 171.1 & 425.9 \\
\hline IIRSA Sur Tramo 5 & $\begin{array}{c}\text { COSTA } \\
\text { SUR }\end{array}$ & 2007 & 25 & 11 & 303.4 & 248.6 & 81.9 & 819.4 & 346.4 \\
\hline $\begin{array}{l}\text { Ovalo Chancay Huaral } \\
\text { Acos }\end{array}$ & $\begin{array}{r}\text { COSTA } \\
\text { CENTRO } \\
\end{array}$ & 2009 & 15 & 3 & 41.6 & 41.2 & 99.0 & 4.2 & 88.6 \\
\hline Mocupe Cayalti Oyotun & $\begin{array}{l}\text { COSTA } \\
\text { NORTE }\end{array}$ & 2009 & 15 & 3 & 24.9 & 24.8 & 99.6 & 0.8 & 56.0 \\
\hline $\begin{array}{l}\text { Longitudinal de la sierra } \\
\text { Tramo } 2\end{array}$ & $\begin{array}{l}\text { SIERRA } \\
\text { NORTE }\end{array}$ & 2014 & 25 & 18 & 269.2 & 222.9 & 82.8 & 82.6 & 294.6 \\
\hline TOTALES & & & & & $3,488.0$ & $3,400.6$ & & $1,442.9$ & $4,898.5$ \\
\hline
\end{tabular}

Fuente: Elaboración propia a partir de la información disponible del Ministerio de Economía y Finanzas $(M E F)$ y proyecciones con datos del Organismo Supervisor de Infraestructura de la Inversión en Infraestructura de Transporte de Uso Público - OSITRAN. Los montos incluyen IGV.

(1) Los documentos de OSITRAN y el MEF, evidencian que el cofinanciamiento del estado a estos contratos, fue del 100\% (USD 3,488 millones). Las obras se construyeron con recursos públicos provenientes del aval estatal. A la fecha se ha pagado $40 \%$ más, que lo que han costado las obras y restan en promedio, 10 años más de contratos.

(2) En el caso de los tramos 2, 3 y 4 de IIRSA Sur, mediante DU 025-2009, DS 235-2010-EF, DU 77-2010, DS 027-2011-EF y DS 135-2011-EF, se autorizó destinar recursos adicionales para financiarlos, los que ascendieron a USD 480.1 millones.

(3) Todos los intervinientes consorciados, forman parte del llamado "Club de la Construcción".

(4) Todos los contratos, han superado los 8 años de ejecución.

Las concesiones responden a un esquema de construcción, operación y transferencia, bajo la modalidad de cofinanciamiento, donde se obliga al Concedente a pagar al Concesionario el monto que no sea cubierto por la recaudación del peaje, hasta cumplir con el monto garantizado denominado Pago Anual por Servicio (PAS).En el caso de los tramos 1 y 5 de 
IIRSA Sur, a pesar de contar con el cofinanciamiento, la recaudación de peajes ya superó el monto de la inversión contractual comprometida en cada contrato.

\section{Imagen 5: Distribución de recaudación de peajes de carreteras concesionadas cofinanciadas.}

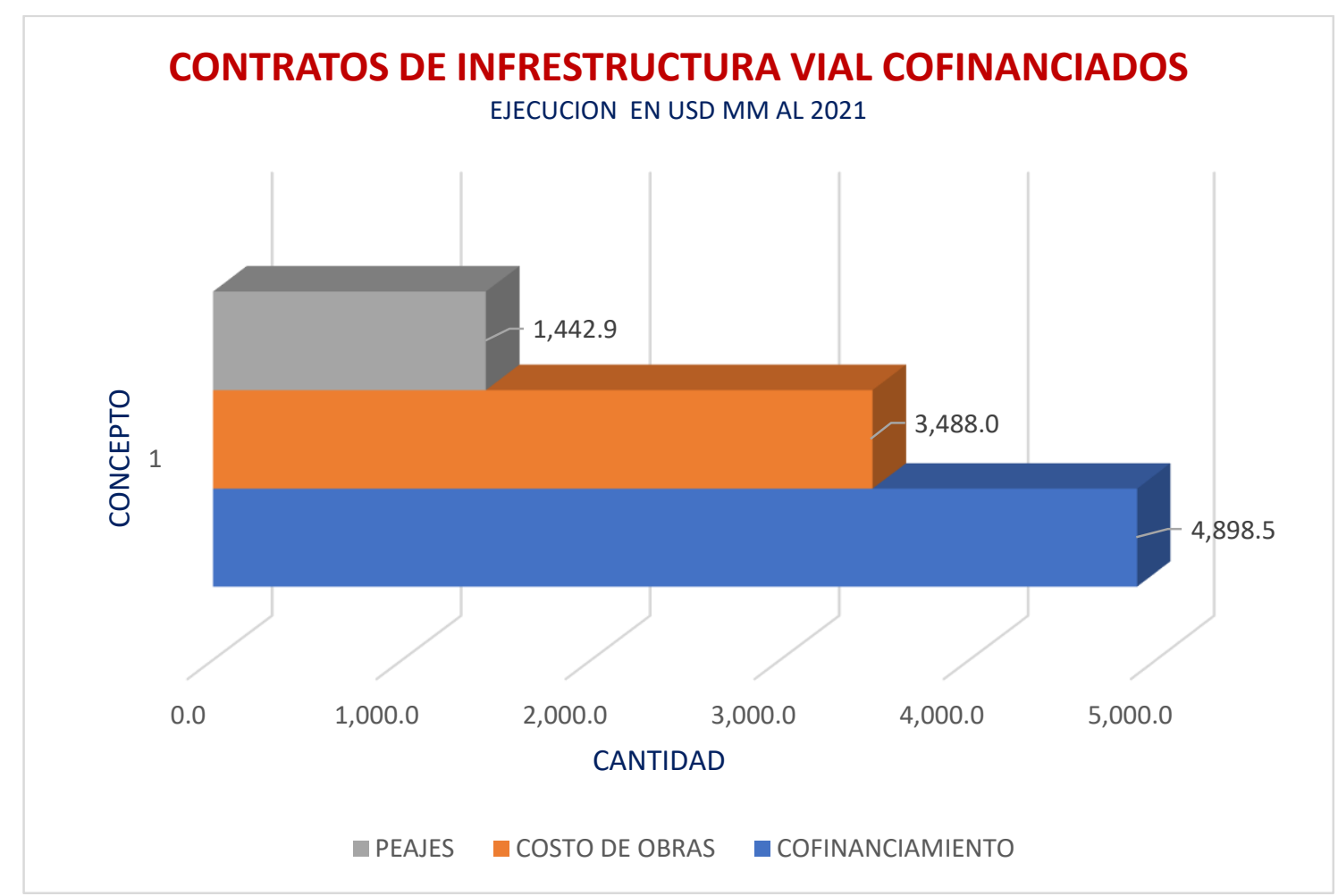

Fuente: Elaboración propia a partir de la información disponible del Ministerio de Economía y Finanzas (MEF) y proyecciones con datos del Organismo Supervisor de Infraestructura de la Inversión en Infraestructura de Transporte de Uso Público - OSITRAN. Los montos incluyen IGV.

Un detalle importante en este tipo de contrataciones, son los sobre precios. Los cálculos que se presentan, no toman en consideración este tema al detalle. En la página 104 del informe Pari, se evidencia que sólo en el caso de los tramos 2, 3 y 4 de la carretera IIRSA Sur, mediante adendas modificó su presupuesto incrementándolo de USD 1,160 millones a USD 3,672 millones (3.16 veces). Este, representa un modus operandi del periodo investigado. Por consiguiente, los sobre montos dinerarios que se comprometieron en esas condiciones, son incalculables. A esto debemos sumarle, lo que ocurrió con las contrataciones de los demás sectores.

La recaudación de peajes de los contratos autosostenibles de los últimos 15 años, es tal vez la fuente más importante de recursos dinerarios en el día a día. La inversión pública en contratos cofinanciados, de igual manera. Solo en el primer grupo, hablamos de 5,139.2 millones de dólares recaudados (15,417.6 soles a un tipo de cambio promedio de 3 soles). 
De acuerdo al modelo, la inversión de los concesionarios, debió lograr un espacio fiscal. No se ha aliviado la presión fiscal en el estado, ni se ha creado el espacio fiscal, que permitiera construir obras nuevas con esos recursos. Solo se ejecutaron sus contratos, ninguna obra más. Cabe entonces preguntarnos: ¿existe un logro de impacto en las vías intervenidas, que justifique haber entregado a privados esta recaudación? La respuesta es no. Sin embargo, debido a la protección constitucional, algunos de los contratos podrían mantenerse vigentes hasta el año 2049.

En términos generales, la concesión de las principales vías del Perú, no ha generado un aporte al desarrollo ambiental sostenible, ni la construcción de nuevas vías, no hay eficiencia, no se han reducido costos, no se ha promovido el bienestar, no fomenta inclusión social y no ofrece beneficios financieros y fiscales. No se han mejorado los niveles de servicio. Los servicios públicos, han desmejorado su calidad, confiabilidad, e incrementado los tiempos de desplazamiento. Los procesos constructivos han demorado más que obras similares (entre 8 y 15 años más). No ha existido transparencia, al publicitar como mega obras, obras de mantenimiento de vías, con el propósito de disponer del flujo de peajes pagados por los vecinos, afectando el interés público.

Dentro del modelo de equilibrio económico financiero del contrato, deben de haberse contemplado variables como los activos a aportar (infraestructura, contrato, capacidad técnico empresarial y capacidad de crédito), el plazo de ejecución de las obras nuevas y el plazo de concesión (optimización, del valor por dinero), el monto de inversión (información de calidad y actualizada de valor de obras y servicios), recaudación para recuperar su inversión (plazo razonable y precisado matemáticamente), la sostenibilidad medio ambiental (no solo cemento y asfalto), el aporte de modernidad (carreteras construidas en 1985) y los ratios de tráfico (eficiencia del servicio).

Siendo el estado, el concedente de todas las APP de infraestructura vial y los peajes recursos públicos, cedidos por plazo determinado mediante los contratos de concesión, en búsqueda de "la optimización del valor del dinero, proveniente de los recursos públicos", es necesario restablecer el equilibrio económico financiero de los contratos de APP, en caso afecte alguna de las partes. Una vez determinado el desequilibrio y cuantificada su envergadura, se debe de ajustar el contrato, a las nuevas condiciones equilibradas. (Ministerio de Economía y Finanzas, 2021) 
No olvidemos que los concesionarios, no son propietarios. Solo administran por plazo determinado, un patrimonio de propiedad del estado. Sin embargo, aparecen como los afectados, aun cuando sus servicios agravian el interés público.

\section{Segundo tipo de casos}

Al margen de la reseña fáctica realizada, que por el artículo 62 de la constitución, estaría cubierta de legalidad, según el Contralor de la República, durante el siglo XXI en el Perú, se han perdido 460 mil millones de soles, por actos de corrupción. La mayor parte de estos recursos, se dilapidaron en el sector construcción. La fuente de esta información es precisamente, el organismo que debería evitarlo: la Contraloría General de la República.

(SHACK, PEREZ, \& PORTUGAL, 2020).

\section{Imagen 6: Contrataciones del Club de la Construcción.}

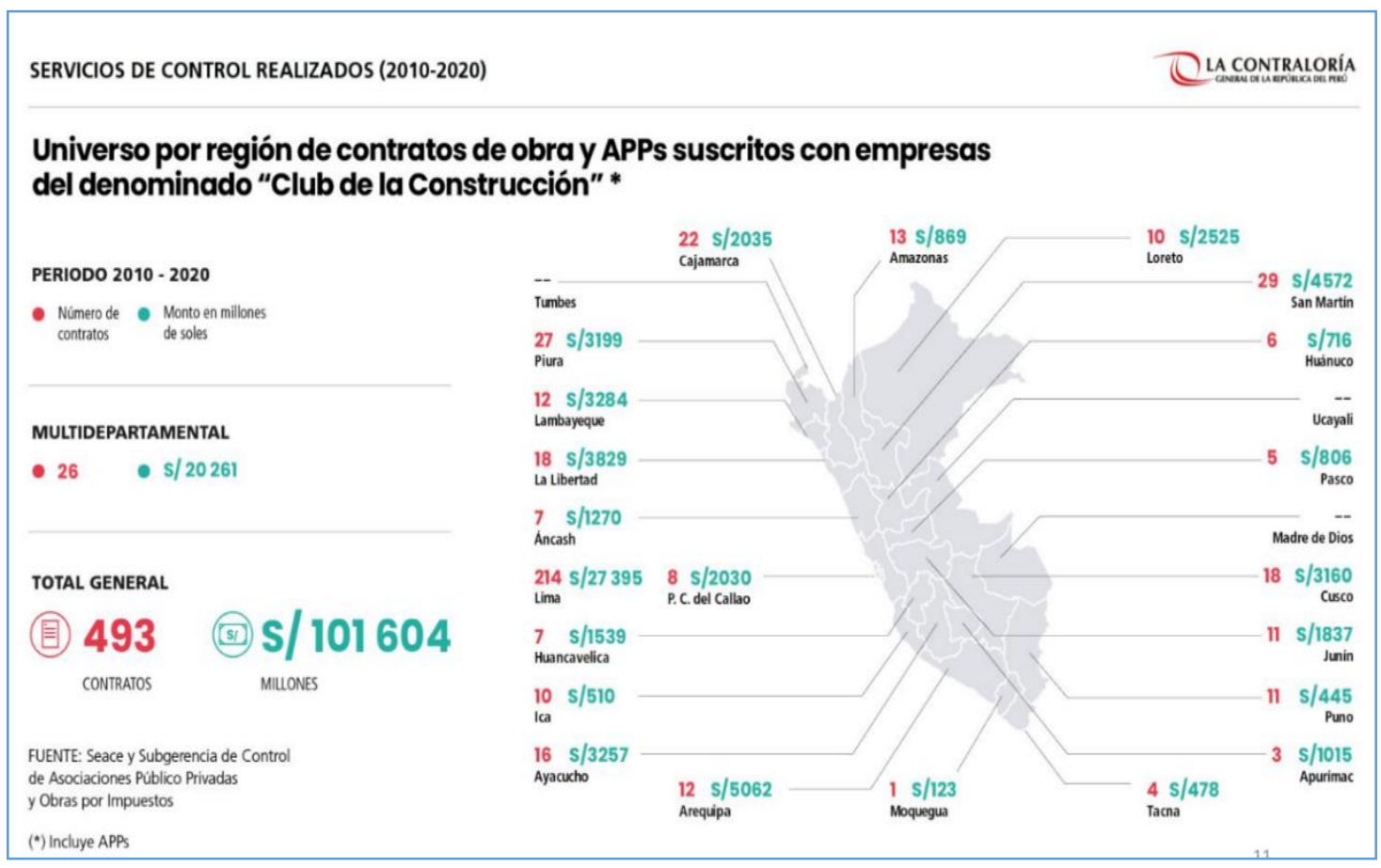

Fuente: Contraloría General de la Republica.

La imagen 6 refleja información de una década (2010-2020). La tercera parte (33\%), corresponde a los contratos que hemos descrito como primer tipo de casos. El 67\% restante (segundo tipo de casos), corresponde a contrataciones del Ministerio de Transportes y comunicaciones. En este cálculo, no se consideran los demás contratos del sector y los de los otros sectores. Es razonable inferir, que las ilícitas condiciones de contratación, se mantuvieron en todas ellas. 
Situación recurrente, desde hace 486 años. Historia de la corrupción en el Perú, página 59, menciona que:

\section{“(...) empieza el abuso del Perú desde aquellos que debieran corregirlo;} se referían así a la colusión de la más alta autoridad, el virrey, con los grupos de intereses locales. El virrey tenía la autoridad centralizadora para otorgar el acceso al poder y podía reforzar así sus redes de patronazo para conseguir ventajas políticas y ventajas privadas. Para gobernar sin mayor oposición interna, los virreyes respaldaban los abusos y excesos, activa y pasivamente, en conjunción con los oidores de las audiencias y otras autoridades. Varios virreyes, participaron del cohecho, al recibir sobornos abierta o encubiertamente, por conceder cargos vacantes y decidir e imponer sentencias judiciales sesgadas." (Quiroz, 2013).

Un caos, organizado por los políticos de turno a lo largo de la historia y que contó con la falta de compromiso, de los profesionales peruanos y una grave falla estructural constitucional. Las políticas de estado durante casi 200 años, han estado ausentes y no han sido prioridad nacional, pues ignoraron por completo esta situación. La falta de un plan de ordenamiento territorial coherente, lo demuestra. Han transcurrido más de 19 años desde la suscripción del Acuerdo Nacional y muchos de los conceptos contenidos en las políticas de Estado, revelan únicamente aspiraciones nacionales que no se han cumplido. Hablamos de todos los sectores. (Acuerdo Nacional, 2016).

\section{RESULTADOS Y DISCUSIÓN}

Entre los principios más importantes, que rigen las contrataciones públicas como las asociaciones públicas privadas ${ }^{8}$, (OSCE, 2019), universalmente se reconocen:

Transparencia. Aquí, existe un grave déficit en las contrataciones de APP, en el Perú. Los supervisores y reguladores, tienen el control de la información. La ciudadanía, no. Hasta ahora, debido a la protección constitucional de los contratos ley, la ciudadanía no conoce los modelos de equilibrio económico financiero que sustentan los contratos ${ }^{9}$. Esta modalidad lleva ejecutándose de esa manera, por lo menos hace 30 años.

\footnotetext{
${ }^{8}$ Decreto Legislativo $\mathrm{N}^{\circ} 1341$

${ }^{9}$ Gutiérrez, W (2019), Defensor del Pueblo. “Estos informes económicos financieros (de los contratos de peajes son) información confidencial (desde los últimos tres gobiernos)”, 16MAY2019
} 
Competencia. Los contratos de APP, se han suscrito en el Perú, fuera del ámbito de aplicación de la $\mathrm{N}^{\circ} 30225^{10}$. Luego, en el transcurso de la ejecución de los contratos, se realizan cambios importantes en los contratos, que varían sustancialmente las condiciones de licitación primigenias y el modelo de equilibrio económico de los contratos originales ${ }^{11}$. Estas modificaciones, por lo general han dependido, de la integridad y la discrecionalidad, de los funcionarios públicos encargados de negociarlas.

Eficacia y Eficiencia. Nuevamente, enorme déficit. Clamoroso déficit. Hasta el 2019 hemos pagado mil millones de dólares en tasas por obras de infraestructura ${ }^{12}$. Si, solo en Lima metropolitana, hemos pagado 3,300 millones de soles en peajes. Si embargo, pese a ese inmenso gasto, un ranking europeo del 2019, de un grupo de 416 ciudades, ubica a Lima, como la séptima ciudad más congestionada del mundo ${ }^{13}$. Con esa enorme inversión, en 8 años, hemos convertido tres carreteras nacionales en 3 avenidas, super congestionadas. Eficacia, eficiencia y efectividad, cero.

Vigencia Tecnológica. En el caso de las vías nacionales, que se sostienen con recaudación de peajes, es bueno conocer, que, no existe una norma específica para la colocación de las garitas de cobro de peajes. Actualmente, su distanciamiento se ha establecido técnica y fácticamente, entre $80 \mathrm{Km}$. y $100 \mathrm{Km}$. En Lima metropolitana, en un total de los 139.6 kilómetros de las concesiones, Lima Expresa y Vías Nuevas de Lima, hay 18 garitas de cobro de peajes. Los 3 tramos planteados, son menores a $80 \mathrm{~km}$. Actualmente, los concesionarios de los peajes de Lima metropolitana, tienen 9 veces, el número de puntos de cobranza de peajes, que hay en la Red Vial Nacional. Se debe cobrar un sólo peaje por tramo. Ninguna de las contrataciones de APP, de este siglo en el Perú muestra un ápice de aportes, a la modernidad y tecnología, de las vías, en detrimento de los usuarios, desfasados en el disfrute de servicios vigentes, en otras partes del mundo. Por ejemplo, pese a haber iniciado la tercera década del siglo XXI, en un atraso tecnológico sin precedentes, en el caso de infraestructura vial, en el Perú no existen islas de servicios en las carreteras (service plazas) ${ }^{14}$, lo que obliga a los conductores de tramos largos a estacionar sus vehículos ligeros y pesados, al borde de las carreteras, con el consiguiente riesgo. Tampoco existe, el peaje electrónico sin vallas, que pierde su sentido de

\footnotetext{
10 "Ley de Contrataciones del Estado"

${ }^{11}$ Congreso de la Republica (2019), Informe Lavajato.

12 INVERMET. Informe mensual de operaciones de concesionarios.

13 Tom Tom. Encuesta mundial de tráfico (2019).

${ }^{14}$ Pennsylvania Turnpike service plazas.
} 
ser, al tenerlas. Recién hace 2 meses, en Chilca se realizan pagos con tarjeta de débito. No son peajes electrónicos.

Sostenibilidad ambiental y social. La OMS ${ }^{15}$, afirma que, respecto del estándar intencional, solo en Lima hay una carencia de áreas verdes, de 56 millones de metros cuadrados $(5,185$ canchas de futbol). Ninguno de los contratos de APP de infraestructura, realiza un aporte al medio ambiente en el Perú.

Equidad. Se trata de que, en las contrataciones públicas de APP, debe de existir un razonable equilibrio entre las prestaciones de las partes. En Lima metropolitana, los concesionarios Lima Expresa y Rutas de Lima, recibirán como beneficios, 15 veces lo que recibirá el concedente ${ }^{16}$. En la Región Lima, los concesionarios Red Vial 5 y Red Vial 6, recibirán como beneficios 15 veces más que el estado ${ }^{17}$. En ambos casos, los contratos terminan dentro de 28 y 15 años. Aritméticamente, esta situación representa un enorme desequilibrio económico financiero, entre las prestaciones de esos contratos. Aquí cabe resaltar, el informe de la Defensoría del Pueblo que evidencia que, durante el fenómeno del niño costero, el estado pagó a los concesionarios de infraestructura vial, en todo el Perú, la suma 1,100 millones de soles, por los daños ocasionados por la naturaleza, en los ámbitos las concesiones. Indudablemente, una falta de equidad total. Adicionalmente, ante la situación de emergencia del presente año, mediante norma expresa ${ }^{18}$, se autoriza a los concesionarios de infraestructura vial ${ }^{19}$, a continuar con el cobro de peajes, pese a tratarse de una situación de emergencia sanitaria, en un claro ejemplo de falta de equidad y sostenibilidad social y ambiental, exponiendo a sus trabajadores al peligro del contagio de la epidemia.

Integridad. En relación a contrataciones en infraestructura vial, existe una sentencia condenatoria (concertación para elevar tasas de peaje) ${ }^{20}$, un proceso en INDECOPI (concertación de precios, para adjudicarse obras) además, de la investigación en el Ministerio Público (sobre precios y pagos de sobornos), al club de la construcción. Esta situación, evidencia un grave déficit de integridad y transparencia, en los participantes en este tipo de contratación. Las contrataciones de otros sectores, como Energía y Minas, Telecomunicaciones, Puertos, Aeropuertos y Ferrovías, no escapan a esta realidad.

\footnotetext{
15 El Comercio, 08ENE2020.

16 (Guerrero M, 2019). Presentación a Regidores Metropolitanos.

${ }^{17}$ OSITRAN. Informes de desempeño: NORVIAL (2002/2018); COVIPERU (2005/2018)

${ }^{18}$ Decreto Supremo N ${ }^{\circ}$ 044-2020-PCM

${ }^{19}$ Oficio Múltiple No $0012-2020-M T C / 19$.

${ }^{20}$ Domingo Arzubialde Elorrieta.
} 
Tratándose de una relación dinámica entre concedente y concesionario, está previsto en los respectivos contratos, la optimización del valor del dinero; se debe de buscar la máxima satisfacción de los usuarios, proveniente de la recaudación (como es el caso de las APP), restableciendo el equilibrio los contratos de APP, en caso afecte alguna de las partes. Es necesario y de interés público, cumplir con los principios más importantes, que rigen universalmente las contrataciones públicas ${ }^{21}$.

Las diferentes situaciones, arriba evidenciadas, las plasmamos de manera esquemática, en la imagen 7.

\section{Imagen 7: Contratos de concesión.}

\section{CARACTERISTICAS DE UNA CONTRATA CION PUBLICA \\ PERU 2021}

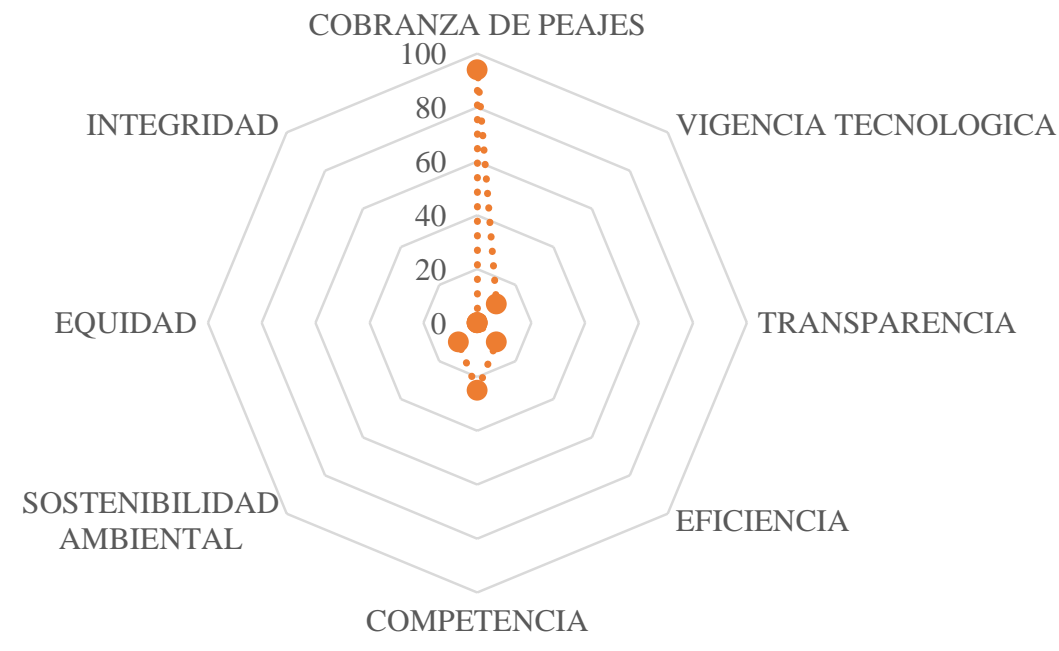

Fuente: Elaboración propia, con datos de la ley de contrataciones del estado.

La presente investigación, se encuentra relacionada con las siguientes políticas del Acuerdo Nacional $^{22}$ :

${ }^{21}$ OSCE.

${ }^{22}$ Acuerdo Nacional. Suscrito el 22JUL2002 
Tabla 3: Políticas de estado

\begin{tabular}{|c|c|c|}
\hline $\begin{array}{l}\text { Política de estado } 24 \\
\text { “Afirmación de un estado } \\
\text { eficiente y transparente”. } \\
\text { Establece que para cualquier } \\
\text { estado fuerte, el estándar más } \\
\text { importante de la gestión pública, } \\
\text { es el de garante estatal y en el } \\
\text { presente caso, lo constituye la } \\
\text { forma como se aporta el } \\
\text { patrimonio estatal, en los mega } \\
\text { contratos } 23 \text { Este estándar, } \\
\text { llamado modelo de equilibrio } \\
\text { económico financiero de los } \\
\text { contratos, debió ser de } \\
\text { conocimiento ciudadano y el } \\
\text { estado, debió evaluar } \\
\text { periódicamente, su } \\
\text { comportamiento; durante por lo } \\
\text { menos las dos últimas décadas. } \\
\text { El estado, no lo ha hecho de } \\
\text { conocimiento de la ciudadanía y } \\
\text { menos, los ha evaluado, } \\
\text { incumpliendo con una política } \\
\text { de estado. }\end{array}$ & $\begin{array}{l}\text { Política de estado 29. "Acceso a } \\
\text { la información, libertad de } \\
\text { expresión y libertad de prensa". } \\
\text { El estado debe de cumplir con } \\
\text { esta política de estadio y } \\
\text { transparentar toda su gestión. } \\
\text { Debemos hacer de conocimiento } \\
\text { público, de que manera se } \\
\text { negociaron los contratos de } \\
\text { asociación público privadas y de } \\
\text { ser necesario, restablecer el } \\
\text { restablecer el equilibrio } \\
\text { económico financiero de ellos. } \\
\text { Esto permitirá, que, con ética, de } \\
\text { manera transparente y sin } \\
\text { corrupción, los recursos que } \\
\text { cobran demás, ros } \\
\text { concesionarios, retornen a su } \\
\text { origen. Un estado eficiente, es } \\
\text { transparente. Desde el } 2020, \text { solo } \\
\text { en el departamento de Lima, se } \\
\text { están destinando a particulares, } \\
\text { más de 1,100 millones de soles } \\
\text { anuales de peajes (recursos que } \\
\text { pagamos todos, a los } \\
\text { concesionarios), por no } \\
\text { restablecer el equilibrio de los } \\
\text { contratos, en este caso, de } \\
\text { infraestructura vial. }\end{array}$ & 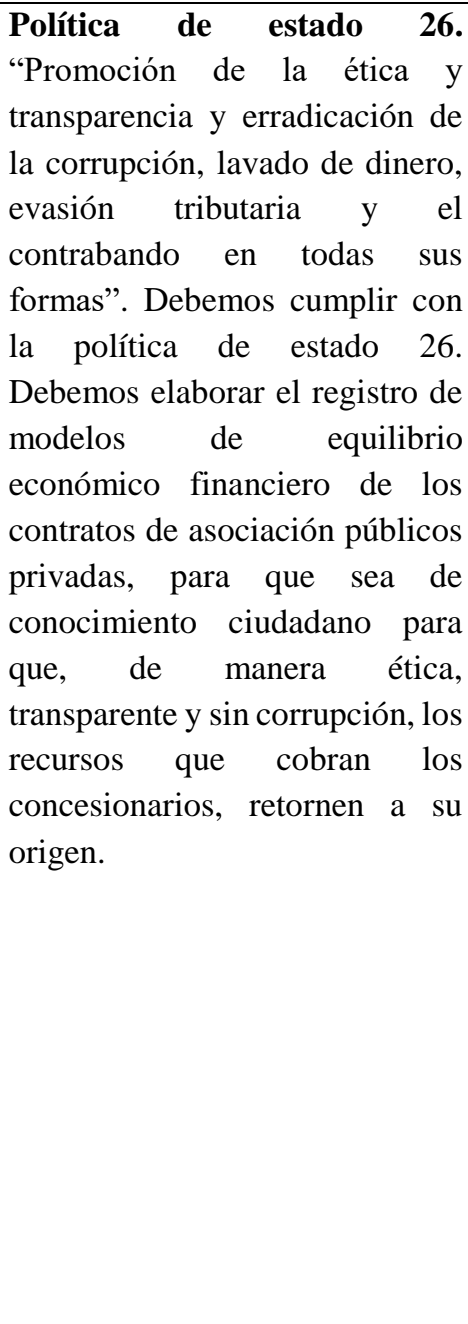 \\
\hline
\end{tabular}

Fuente: Elaboración propia, con datos del Acuerdo Nacional.

\section{De igual manera, el Tribunal Constitucional, establece que:}

“(...) el interés público tiene que ver con aquello que beneficia a todos; por ende, es sinónimo y equivalente al interés general de la comunidad. Su satisfacción constituye uno de los fines del Estado y justifica la existencia de la organización administrativa. La administración estatal, constituida por órganos jerárquicamente ordenados, asume el cumplimiento de los fines del Estado teniendo en cuenta la pronta y eficaz satisfacción del interés público." (Constitucional, 2004).

En la legislación comparada de Argentina, Brasil, Chile, Colombia, México, Panamá, Salvador y Uruguay, desde el año 2004, han ido perfeccionando los sistemas de contratación

\footnotetext{
${ }^{23}$ Perú 21. 29AGO2016. Megaproyectos investigados.
} 
de asociaciones publico privadas. Ninguno de los países mencionados, les ofrece blindaje constitucional. Es preciso recalcar, que las condicionantes de contratación, son de mucho mayor calidad que las peruanas.

(Congreso de Argentina, 2016), (Congreso de Brasil, 2004), (Gobierno de Chile, 2017), (Congreso de Colombia, 2012), (Asamblea Nacional del Ecuador, 2015), (Asamblea Legislativa de México, 2012), (Congreso del Paraguay), (Asamblea Nacional de Panamá, 2019), (Asamblea Legislativa de El Salvador, 2013), (Gobierno del Uruguay, 2011).

Es más, desde que se promulgó el 31 de diciembre de 1993, ese cuerpo normativo constitucional ha sufrido 22 modificaciones, algunas estructurales y otras, no tanto, como remover la firma del autor de nuestra carta magna, en el 2001. Se han producido 4 de tipo económico, 6 en el ámbito de derechos humanos y 12 en el ámbito político. (Sistema Peruano de Información Jurídica, 2020).

\section{Imagen 8: Modificaciones de la Constitución peruana.}

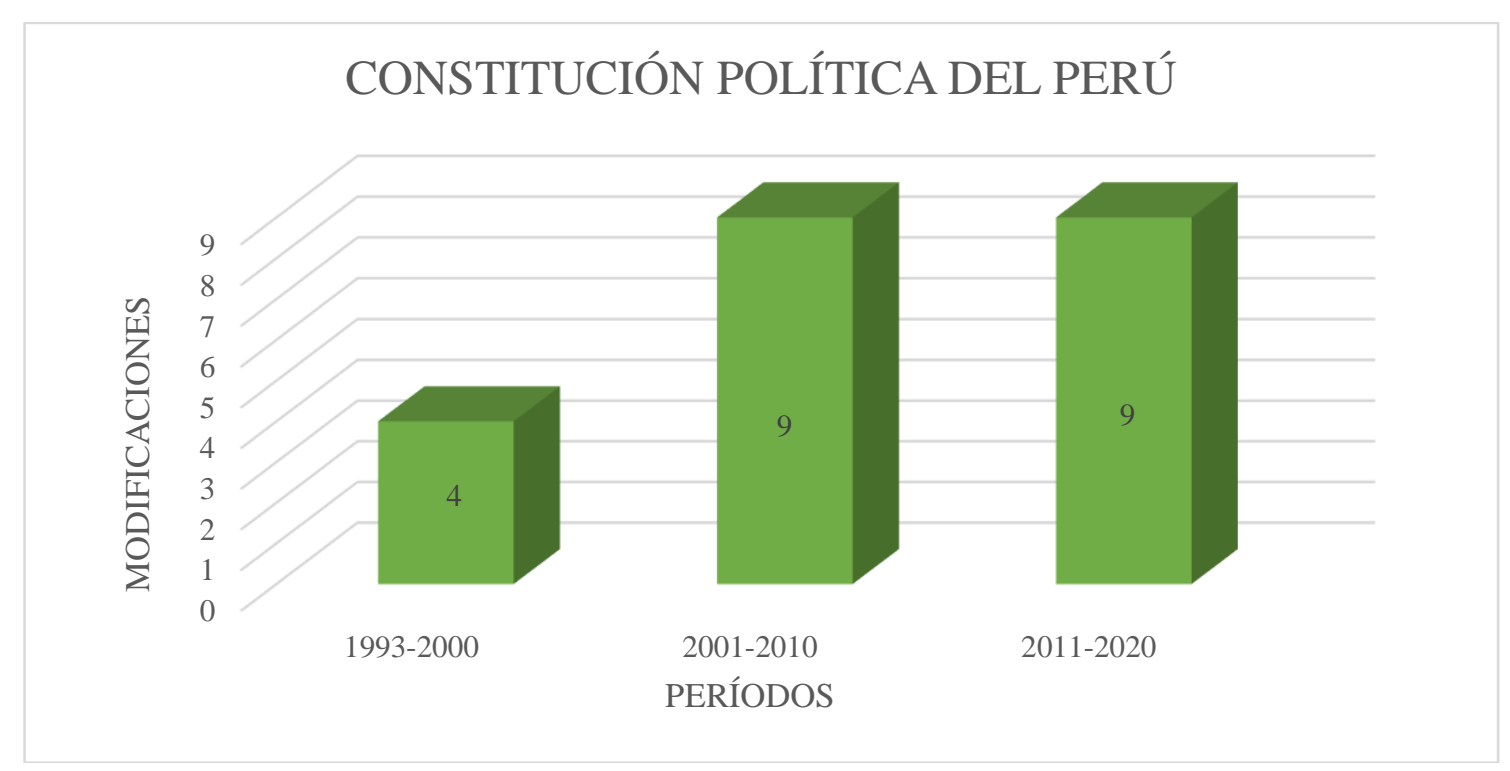

Fuente: Sistema Peruano de Información Jurídica. Elaboración propia

La mayor cantidad de modificaciones, se ha producido durante el presente siglo. El detalle de estas modificaciones en la siguiente tabla 4. 
Tabla 4: Modificaciones a la Constitución Política del Perú desde 1993.

\begin{tabular}{|c|c|c|c|c|}
\hline CAMBIO & LEY & ACCION & $\begin{array}{l}\text { ARTÍCULOS } \\
\text { QUE SE } \\
\text { MODIFICAN }\end{array}$ & $\begin{array}{l}\text { FECHA } \\
\text { DE } \\
\text { CAMBIO }\end{array}$ \\
\hline 1 & 26470 & $\begin{array}{c}\text { ELIMINA LA POSIBILIDAD DE UTILIZAR UN HABEAS DATA O AMPARO } \\
\text { PARA RECTIFICAR CUALQUIER "HECHO U OMISIÓN" COMETIDO POR LA } \\
\text { PRENSA, AUTORIDAD O PERSONA QUE VULNERE UN DERECHO } \\
\text { CONSTIOTUCIONAL }\end{array}$ & 200 & 12-Jun-95 \\
\hline 2 & 26472 & $\begin{array}{c}\text { MODIFICA EL CANON PARA QUE SE INDIQUE QUE ESTA CONFORMADO } \\
\text { POR LOS INGRESOS Y VENTAS OBTENIDOS POR EL ESTADO EN LA } \\
\text { EXPLOTACIÓN DE RECURSOS NATURALES EN CADA ZONA, Y QUE NO } \\
\text { SOLO SE CONFORMABA POR EL IMPUESTO A LA RENTA GENERADO POR } \\
\text { DICHAS ACTIVIDADES } \\
\end{array}$ & 77 & 13-Jun-95 \\
\hline 3 & 27365 & ELIMINA LA REELECCIÓN INMEDIATA PRESIDENCIAL & 112 & 5-Nov-00 \\
\hline 4 & 27365 & $\begin{array}{l}\text { INTRODUCE LA DISPOSICIÓN TRANSITORIA ESPECIAL PARA QUE EL } \\
\text { GOBIERNO DE VALENTIN PANIAGUA Y LOS CONGRESISTAS SELEGIDOS EL } \\
\text { AÑO 2000, CULMINEN SU REPRESENTACIÓN EL 26JUL2001 }\end{array}$ & $\begin{array}{l}\text { CREA DISPOSICION } \\
\text { TRANSITORIA } \\
\text { ESPECIAL }\end{array}$ & 5 -Nov-00 \\
\hline 5 & 27600 & $\begin{array}{l}\text { SE SUPRIME LA FIRMA DE ALBERTO FUJIMORI EN EL TEXTO DE LA } \\
\text { CONSTITUCIÓN }\end{array}$ & $\begin{array}{l}\text { CREA ARTICULO DE } \\
\text { SUPRESIÓN DE FIRMA }\end{array}$ & 16-Dic-01 \\
\hline 6 & 27680 & $\begin{array}{l}\text { SE MODIFICA LA TOTALIDAD DEL CAPITULO XIV, EL CUAL TRATA } \\
\text { ACERCA DE LA DESENTRALIZACIÓN, INTRODUCIENDOI MEDIDAS QUE } \\
\text { ELIMINEN EL ENFOQUE CENTRALIZADO DE LA CONSTITUCION. }\end{array}$ & $\begin{array}{l}\text { TOTALIDAD DEL } \\
\text { CAPIYULO XIV } \\
\quad 188 \text { A } 199\end{array}$ & 7-Mar-02 \\
\hline 7 & 28389 & CIERRE DEL REGIMEN PENSIONARIO CREADO POR LA LEY 20530 & $\begin{array}{l}11,103, \\
\text { PRIMERA } \\
\text { DISPOSICIÓN } \\
\text { TRANSITORIA Y } \\
\text { FINAL } \\
\end{array}$ & 17-Nov-04 \\
\hline 8 & 28390 & $\begin{array}{l}\text { PERMITE QUE LOS GOBIERNOS REGIONALES PUEDAN CREAR, MODIFICAR } \\
\text { Y ELIMINAR CONTRIBUCIONES Y TASAS. ADEMÁS, SE LES OTORGA } \\
\text { INICIATIVA LEGISLATIVA }\end{array}$ & 74,107 & 17-Nov-04 \\
\hline 9 & 28480 & $\begin{array}{l}\text { AUTORIZÓ EL VOTO Y LA PARTICIPACIÓN CIUDADANA DE LA DE LA } \\
\text { FUERZA ARMADA Y LA POLICÍA NACIONAL Y PROHIBE EL LIMITE AL } \\
\text { SUFRAGIO }\end{array}$ & 31,34 & 30-Mar-05 \\
\hline 10 & 28484 & $\begin{array}{l}\text { CAMBIA EL NOMBRE DE SUPERINTENDENCIA DE BANCA Y SEGUROS (SBS) } \\
\text { POR LA DE SUPERINTENDENCIA DE BANCA, SEGUROS Y } \\
\text { ADMINISTRADORAS PRIVADAS. }\end{array}$ & $87,91,96,101$ & $5-A b r-02$ \\
\hline 11 & 28607 & $\begin{array}{l}\text { PARA PODER POSTULAR PARA PRESIDENTE DE LA REPÚBLICA, VICE } \\
\text { PRESIDENTE, CONGRESISTA, PRESIDENTE REGIONAL (O ALCALDE), } \\
\text { ALCALDE, LOS ALCALDES (O PRESIDENTES REGIONALES QUE POSTULEN } \\
\text { AL CARGO) DEBEN RENUNCIAR A SU PUESTO } 6 \text { MESES ANTES DE LAS } \\
\text { ELECCIONES. }\end{array}$ & $91,191,204$ & 4-Set-05 \\
\hline 12 & 29401 & $\begin{array}{l}\text { MODIFICA LA SUSTENTACIÓN DEL PRESUPUESTO PÚBLICO ANTE EL } \\
\text { CONGRESO. LOS MINISTROS DEBEN AHORA PREVIAMENTE SUSTENTAR } \\
\text { LOS RESULTADOS Y METAS DE LA EJECUCIÓN DEL PRESUPUESTO DEL } \\
\text { AÑO ANTERIOR Y LOS AVANCES DE LA EJECUCIÓN DEL PRESUPUESTO } \\
\text { DEL AÑO FISCAL CORRESPONDIENTE. }\end{array}$ & 80,81 & 8-Set-09 \\
\hline 13 & 29402 & SE INCREMENTA EL NÚMERO DE CONGRESISTAS DE 120 A 130. & 90 & 8-Set-09 \\
\hline 14 & 30305 & $\begin{array}{l}\text { ELIMINA LA REELECCIÓN INMEDIATA DE ALCALDES Y GOBERNADORES } \\
\text { REGIONALES. }\end{array}$ & $191,194,203$ & 10-Mar-15 \\
\hline 15 & 30558 & $\begin{array}{l}\text { SE INDICA QUE LAS DETENCIONES POLICIALES NO DURARÁN MAS DEL } \\
\text { TIEMPO ESTRICTAMENTE NECESARIO PARA LA REALIZACIÓN DE LAS } \\
\text { INVESTIGACIONES. }\end{array}$ & 2.24 & 9-May-17 \\
\hline 16 & 30588 & $\begin{array}{l}\text { RECONOCE EL DERECHO DEL ACCESO AL AGUA COMO UN DERECHO } \\
\text { CONSTITUCIONAL. }\end{array}$ & INCORPORA 7-A & 22-Jun-17 \\
\hline 17 & 30650 & $\begin{array}{l}\text { AGREGA QUE EL PLAZO DE PRESCRPCIÓN DE LA ACCIÓN PENALSE } \\
\text { DUPLICA EN CASO DE LOS DELITOS CONTRA LA ADMINISTRACIÓN } \\
\text { PUBLICA O EL PATRIMONIO DEL ESTADO Y QUE LA ACCIÓN PENAL ES } \\
\text { IMPRESCRIPTIBLE EN LOS SUPUESTOS MAS GRAVES. ANTERIORMENTE, }\end{array}$ & 41 & 20-Ago-17 \\
\hline 18 & 30651 & $\begin{array}{l}\text { OTORGA AL PRESDENTE DEL PODER JUDICIAL LA FACULTAD DE } \\
\text { INTERPONER ACCIONES DE INCONSTITUIONALIDAD. }\end{array}$ & 203 & 20-Ago-17 \\
\hline 19 & 30904 & $\begin{array}{l}\text { SE ELIMINA EL CONSEJO NACIONAL DE LA MAGISTRATURA Y SE CREA LA } \\
\text { JUNTA NACIONAL DE JUSTICIA, LA CUAL CUENTA CON MAS FUNCIONES Y } \\
\text { TIENE REQUISITOS DE INGRESO MAS RESTRICTIVOS. }\end{array}$ & $\begin{array}{l}\text { TODO EL CAPITULO IX } \\
150 \mathrm{~A} 157\end{array}$ & 10-Ene-19 \\
\hline 20 & 30905 & $\begin{array}{l}\text { SEÑALA QUE EL FINANCIAMIENTO DE LOS PARTIDOS POLÍTICOS SE RIGE } \\
\text { POR LEY CONFORME A CRITERIOS DE TRANSPARENCIA Y RENDICIÓN DE } \\
\text { CUENTAS Y TIENE LAS EXCEPCIONES Y TOPES CORRESPONDIENTES. } \\
\text { ADEMÁS, SE INDICA, QUE SOLO SE AUTORIZA LA DIFUSIÓN DE } \\
\text { PROPAGANDA ELECTORAL EN MEDIOS DE COMUNICACION RADIALES Y } \\
\text { TELEVISIVOS MEDIANTE FINANCIAIENTO PÚBLICO INDIRECTO. }\end{array}$ & 35 & 10-Ene-19 \\
\hline 21 & 30906 & ELIMINA LA REELECIÓN INMEDIATA DE CONGRESISTAS. & INCORPORA 90-A & 10-Ene-19 \\
\hline 22 & 31043 & $\begin{array}{l}\text { LAS PERSONAS CON SENTENCIAS EN PRIMERA INSTANCIA POR DELITOS } \\
\text { DOLOSOS EN CALIDAD DE AUTORES O CÓMPLICES NO PUEDEN POSTULAR } \\
\text { A CARGOS DE ELECCIÓN POPULAR. ASI MISMO, ESTÁN IMPEDIDAS DE } \\
\text { EJERCER LA FUNCIÓN PÚBLICA. }\end{array}$ & INCORPORA 34-A, 39-A & 15 -Set-20 \\
\hline
\end{tabular}

Fuente: Sistema Peruano de Información Jurídica. Elaboración propia 
Esta investigación, enfatiza y pretende combatir, las carencias en la conducta y ética, de los funcionarios públicos peruanos, para desarrollar su labor, como garantes del patrimonio estatal, en defensa de los usuarios y el interés público. Por ello, permitiéndolo la normatividad y los contratos de APP de Infraestructura, deben de restablecerse en el Perú, la integridad, el uso social de la tecnología y los principios que rigen las contrataciones, en todo el mundo.

\section{CONSIDERACIONES FINALES}

Antes de 1993, la constitución y la ley estaban por encima de los contratos que regulan la actividad empresarial del estado. Ahora, durante la vigencia del artículo constitucional cuestionado, solo en el siglo XXI un tipo de estas contrataciones, debido a la corrupción, según el órgano de control habría producido pérdidas al estado, por 460 mil millones de soles. No se incluyen en este cálculo, las considerables recaudaciones de las APPs, hasta la culminación de sus contratos. Un gravísimo perjuicio, una de cuyas aristas se refleja en la incapacidad de atención a la pandemia (200 mil fallecidos); lo que nos erige como el país que peor combatió al covid-19.

Esto demuestra, que la carta magna y la normatividad peruana a partir de 1993, presentan serias falencias y una grave fisura estructural. El cálculo de costo beneficio (ACB), debió ponerse en blanco y negro y de manera pública, al momento de suscribirse contratos; ya que los concedentes, ofrecían el patrimonio estatal, como aporte al contrato y debieron recibir como contraparte de los beneficios del negocio, algo equilibrado y planificado. La protección constitucional, que les ofrece y su contradicción con las políticas de estado, representa un escudo anticonstitucional e ilegal.

Esto ha permitido contrataciones (aunque en este caso nos referimos solo a infraestructura vial), que, aduciendo la falta de recursos públicos, para ejecutar y mantener obras, que cerrarían brechas de infraestructura y hasta ahora no son identificadas ${ }^{24}$. Tanto la falta de recursos, como las brechas a cubrir, fueron simuladas. La cantidad de recursos, dispuestos en agravio del interés público, es multimillonaria y hasta abril del 2018, solo en este tipo de infraestructura, procedían de obras que ya existían antes de firmar los contratos ${ }^{25}$.

El poder del estado, debe reorientarse al bienestar general y la carta magna y la normatividad, deben de legislar a favor, del interés público. Los contratos ley, si han sido fruto de corrupción

\footnotetext{
${ }^{24}$ SNIP/Invierte.pe

${ }^{25}$ Carretera Panamericana Norte hasta Puente Piedra, carretera Panamericana Sur hasta Pucusana y carretera Ramiro Prialé hasta Huachipa.
} 
no pueden ser constitucionalmente; pierden su condición de contratos ley. No se le puede impedir al Poder Legislativo, ejercer su atribución constitucional. De ser así, en el Perú, estaría amparando la comisión de delitos y contraviniendo, el articulo $2.14^{\circ}$, de la propia Carta Magna.

El instrumento constitucional, evidencia un confuso mapa conceptual, que requiere de una reestructuración lógica. Un cúmulo de artículos (no todos) sin conexión ni criterio lógicos, que se contradicen unos con otros, no pueden regir los destinos del país.

Como consecuencia de esta grave falla estructural, los contratos ley de infraestructura vial, suscritos bajo la carta magna de 1993, contienen notorios desequilibrios económicos financieros en sus contratos (en agravio del interés público), que han originado: a) se viene pagando tarifas, que no responden a una estructura técnica, en agravio del interés público. b) No ha existido una inversión privada cabal, pues en la mayoría de las concesiones, los concesionarios disponen gratuitamente de la infraestructura vial existente. c) La mayoría, iniciaron cobranza de tarifas, a la suscripción del contrato. d) No existe un reparto objetivo entre las partes ni sostenibilidad financiera ni ventajas socio económicas de los proyectos. e) Los contratos agravian el interés público.

Se debe hacer un corte en la contratación citada, contrastando el resultado con un comparador público de precios y una revisión del propósito de los organismos reguladores, que destinan ingentes recursos del erario nacional para supervisar contratos, que no requieren tal infraestructura.

La etapa principal del proceso de formulación de las políticas públicas, es la evaluación y la continuidad o cambio. Una política pública, debe tener sustento constitucional y en este caso, defender el interés de los consumidores y usuarios. En consecuencia, se hace absolutamente necesaria una evaluación y modificación del artículo $62^{\circ}$ de la Constitución política del Perú. Debemos comenzar por hacer concertar, acordar, conciliar, enlazar, converger, artículos $1^{\circ}$, $2.1^{\circ}, 2.2^{\circ}$ y $2.14^{\circ}, 59^{\circ}, 62^{\circ}$ y $65^{\circ}$ de la Carta Magna. La historia y el artículo $206^{\circ}$, lo permiten.

\section{LISTA DE REFERENCIAS}

Argentina, C. d. (16 de noviembre de 2016). Ley $\mathrm{N}^{\circ}$ 27328. Contratos de participación publico privada. Buenos Aires, Argentina.

Atanasio Fuentes, M. (2018). Derecho constitucional filosófico. Lima: Centro de estudios constitucionales. 
Brasil, C. n. (30 de diciembre de 2004). Ley $\mathrm{N}^{\circ}$ 11.079. Instituye reglas generales de licitación y contratación, de alianzas público privadas, en el ambito de la administración pública. Brazilia, Brasil.

Chile, M. d. (25 de noviembre de 2017). Decreto $\mathrm{N}^{\circ}$ 900. Fija texto refundido, coordinado y sistematizado del DFL MOP $N^{\circ} 164$, de 1991 Ley de concesiones de obras públicas. Valparaiso, Chile.

Chipoco Tovar, E. (1989). Constituciones Peruanas 1822-1979. Lima.

Cifuentes, P. (2019). ¿Que sabemos de las constituciones de otros países? El mercurio.

Colombia, C. d. (10 de enero de 2012). Ley $\mathrm{N}^{\circ}$ 1508. Por la cual se establece el régimen jurídico de las Asociaciones Público Privadas, se dictan normas orgánicas de presupuesto y se dictan otras disposiciones. Bogotá, Colombia.

Congreso de Argentina. (2016). Ley $\mathrm{N}^{\circ}$ 27328. Contratos de participación público privada. Buenos Aires, Argentina.

Congreso de Brasil. (2004). Ley $\mathrm{N}^{\circ}$ 11.079. Instituye reglas generales de licitacion y contratacion, de alianzas público privadas, en el ambito de la administracion pública. Brazilia, Brasil.

Constitucional, T. (2004 de Julio de 2004). Exp. № 0090-2004-AA/TC-Lima. JUAN CARLOS CALLEGARI HERAZO. Arequipa, Perú.

De Vidaurre, M. (2019). Plan del Perú. Lima: Centro de estudios constitucionales.

Ecuador, A. N. (15 de diciembre de 2015). Ley organica de incentivos, para asociaciose público privadas. Quito, Ecuador.

Hernandez Sampieri, R., Fernandez Collado, C., \& Baptista Lucio, P. (2014). Metodología de la investigación. México DF.

Masías, F. (2019). Breves nociones de la ciencia constitucional. Lima: Centro de estudios constitucionales.

México, A. L. (16 de enero de 2012). Ley de asociaciones público privadas. México DF, México.

Ministerio de Economía y Finanzas. (2021). Que es una APP. Obtenido de https://www.mef.gob.pe/es/?id=336\&option=com_content\&language=es$\mathrm{ES} \&$ view $=$ article $\&$ lang $=\mathrm{es}-\mathrm{ES}$

Montoya Vivanco Ivan. (2008). Aspectos relevantes del delito de colusión tipificado en el artículo Nº 384 del código penal peruano. Gaceta Jurídica, 100. 
OSCE. (2019). Ley de contrataciones del estado. Lima.

OSITRAN. (2021). Reporte estadístico. Supervision de contratos de la red vial. Lima.

Pacheco, T. (2015). Cuestiones constitucionales. Lima: Centro de estudios constitucionales.

Panamá, A. N. (2019). Ley No 93. Crea el regimen de asocianes publico privadas para el desarrollo como incentivo a la inversion privada, al desarrollo social y a la creacion de empleos. Ciuidad de Panamá, Panamá.

Paraguay, C. d. (1 de abril de 2016). Ley $\mathrm{N}^{\circ}$ 5102. Promocion de la inversión en infraestructura pública y ampliación y mejoramiento de los bienes y servicios a cargo del estado. Asunción, Paraguay.

Pardo y Aliaga , F., \& Atanasio Fuentes, M. (2019). Sátira constitucional peruana. Lima: Centro de estudios constitucionales.

Pari, J. C. (2016). Comisión Investigadora, Congreso de la República. Lima.

Quiroz, A. (2013). Historia de la corrupcion en el Perú. Lima.

Ramos Nuñez, C. (2017). Las constituciones del Perú. Lima: Centro de estudios constitucionales.

Salvador, A. L. (23 de mayo de 2013). Decreto $\mathrm{N}^{\circ}$ 379. Ley especial de asocios público privados. San Salvador, El Salvador.

San Clemente-Arciniegas, J. (2019). Corrupción, orden público y regulación economica en Colombia. Juridicas, 105/124.

Silva Santisteban, J. (2015). Curso de derecho constitucional. Lima: Centro de estudios constitucionales.

Sistema Përuano de Información Jurídica. (2020). Reformas a la constitución peruana. Lima.

Suprema, S. p. (2003). Expediente $N^{\circ}$ 20-2003-AV. Recurso de Nulidad caso Mobetek. Lima, Perú.

Uruguay. (19 de julio de 2011). Ley $\mathrm{N}^{\circ}$ 18786. Ley de participación público privada. Montevideo, Uruguay.

Villaran, L. (2016). La constitucion peruana comentada. Lima: Centro de estudios constitucionales. 